\title{
POSTMODERNIDAD Y LATINOAMERICA (CON UN MODELO PARA LA NARRATIVA POSTMODERNA)
}

POR

\author{
ALFONSO DE TORO \\ Kiel Universität
}

En todas las ficciones, cada vez que un hombre se enfrenta con diversas alternativas, opta por una y elimina las otras; en la del casi inextricable Ts'ui Pên opta - simultáneamente- por todas. Crea, así, diversos porvenires, diversos tiempos, que también proliferan y se bifurcan $[. .$.$] todos los desenlaces ocurren;$ cada uno es el punto de partida de otras bifurcaciones.

[...]

Creía en infinitas series de tiempos que se aproximan, se bifurcan, se cortan o que secularmente se ignoran, abarca todas las posibilidades.

(Borges, El jardin de senderos que se bifurcan, 170, $172)^{1}$.

\section{INTRODUCCION}

Las siguientes páginas pretenden solamente proponer algunas ideas con respecto al fenómeno de la postmodernidad en relación con la narrativa latinoamericana. Esta restricción es necesaria frente a la amplitud y complejidad del debate de la postmodernidad. Intentamos, eso sí, poner en manifiesto que la postmodernidad es describible partiendo de una serie de elementos bases, y de esta forma también la novela latinoamerica postmoderna.

\section{GENERALIDADES}

Lo que denota el término 'postmodernidad'y cuáles son sus características como sistema sigue siendo, hoy en día, a pesar de un diluvio de publicaciones, altamente discutido, tanto dentro de una disciplina determinada como en la

\footnotetext{
${ }^{1}$ Ficciones. Madrid: Bruguera, 1985; cf. también las similitudes con Gilles Deleuze/Félix Guattari: Rhizome. Berlin, 1977; París, 1976.
} 
semiótica de la cultura: existen tan variadas tesis como autores que se han manifestado al respecto. El término se ha convertido con el tiempo en una metáfora poco convincente, en una idea fija, que se encuentra en todos los campos.

Frente a semejante situación es imprescindible aclarar las nociones del término en cuestión, y especialmente dentro de la ciencia literaria, donde observamos un fenómeno similar a aquél cuando surgieron el estructuralismo, la semiótica y la teoria de la recepción, cuando la terminología de estas disciplinas fue (y lo es aún) degradada a conceptos eclécticos que nada definían ni precisaban. Una semejante Babilonia impide una discusión seria, y ha conducido a que autores pertenecientes a siglos tan lejanos se los califique de postmodernos, tales como Aristóteles y Rabelais, Cervantes y Gracián, Sterne y Baudelaire, Artaud y Joyce, Beckett y Borges, Heißenbüttel y Norman Mailer, Vonnegut y A. Robbe- Grillet, como así últimamente también la novela hispanoamericana en su totalidad ${ }^{2}$ y no olvidemos a Nietzsche y Heidegger, Lyotard y Vattimo, U. Eco y muchos otros.

Frente a esta definición inflacionaria, que a la vez es ahistórica, observa Umberto Eco en su Postille a Il nome della rosa en forma sarcástica, que pronto llegaremos a Homero ${ }^{3}$.

\section{GENEALOGIA, HISTORIA Y PERIODIZACION DE LA POSTMODERNIDAD.}

\subsection{Breve genealogía e historia del término 'Postmodernidad' y sus campos.}

Si el término 'Post-Modernidad' tanto semántica, histórica como sistemáticamente pretende tener algún sentido, no se debería partir de la premisa que el momento en el que manifestamos algo, es el 'moderno' o 'vanguardista', ya que de esta forma la postmodernidad no podría tener lugar, lo cual sería insensato. Por esta razón es aconsejable entender estos términos históricamente, como lo desarrollaremos más adelante.

${ }^{2}$ Una semejante tendencia se encuentra en los trabajos de J. Barth: "The Literary of Exhaustion", en Atlantic Monthly 220 (1967): 29-43; "The Literature of Replenishment: Postmodernist Fiction", en Atlantic Monthly 245 (1980): 65-71.

3 U. Eco: "Postille (1983)", en Il nome della rosa (1980), Milano ( $\left.{ }^{6} 1985\right), 528$ : Malauguratamente "post-moderno" è un termino buono à tout faire. Ho l'impressione che oggi lo si applichi a tutto ciò che piace a chi lo usa. D'altra parte sembra chi sia un tentativo di farlo slittare, all'indietro: prima sembrava adattarsi ad alcuni scrittori o artisti operanti negli ultimi vent'anni, poi via via è arrivato sino a inizio secolo, poi più indietro, e la marcia continua, tra poco la categoria del post-moderno arriverà a Omero.

La concepción de Eco es ahistórica: Credo tuttavia che il post-moderno non sia una tendenza circoscrivibile cronologicamente, ma una categoria spirituale, o meglio un Kunstvollen, un modo di operare. Potremmo dire che ogni epoca ha il propio post-moderno, cosi come ogni epoca avrebbe il propio manierismo (tanto che mi chiedo se post-moderno non sia il nome moderno del Manierismo como categoria metastorica); (Ibid.: 528). 
Bajo un punto de vista histórico-cultural tenemos que diferenciar el término 'post-modernidad' actual de aquél que, estando relacionado con la historiografía y las ciencias naturales, se encontraba en oposición al de 'modernidad', entendido como aquél que marca el comienzo del Renacimiento (1500) o de la época moderna inaugurada con Descartes (1596-1650) y la fundación de la mathesis universalis. Ese término se denominaba 'postmodernismo' y marca una época que comienza alrededor de 1875 (según Toynbee). Por otra parte tenemos un postmodernismo a partir de 1917 (según Pannwitz) que se encuentra en oposición a la modernidad cultural-literaria que comienza en $1985^{4}$. Frente a lo expuesto tampoco se debe confundir el término 'postmodernidad' con aquél de 'postmodernismo' de Federico Onís, que es de naturaleza de tipo literaria. Según éste, comienza el postmodernismo, como reacción al 'modernismo' (1850), alrededor de 1905-1914, y poco o nada tiene en común con el término 'postmodernidad' que discutiremos aquí

Bajo 'postmodernidad' entendemos un fenómeno histórico-cultural ${ }^{6}$, que aparece después de la 'modernidad' (ésta va desde 1850-ca. 1960 ..., de Baudelaire a la nueva novela y nouveau roman), es decir, en el úl timo tercio de nuestro siglo.

Entendemos la postmodernidad no sólo como una consecuencia de la modernidad, como una 'habitualización', una continuación y culminación de ésta, sino como una actividad de 'recodificación iluminada, integrativa y pluralista', que retoma y reconsidera un amplio paradigma, en especial de la cultura occidental, pero no solamente de ésta, con la finalidad de repensar la tradición cultural y de esta forma finalmente abrir un nuevo paradigma, donde se termina con los metadiscursos totalizantes y excluyentes y se boga por la 'paralogia', por el disenso y la cultura del debate. Yo osaría calificar la postmodernidad como un "Renacimiento recodificado". Entendemos bajo esta

\footnotetext{
${ }^{4}$ v. nota 6.

${ }^{5} \mathrm{Cf}$. Federico de Onís: Antología de la poesia española e hispanoamericana. Madrid, 1934; Con respecto al postmodernismo en el ámbito hispánico: Octavio Corvalán: El postmodernismo, la literatura hispanoamericana entre dos guerras mundiales. New York: Las Américas Pub. Co., 1961; Pedro Salinas: "El cisne y el buho; apuntes para la historia de la poesía modernista", en Literatura española del siglo XX. México (1949), 45-65;Beatriz Sarlo: "La poesía post-modernista", en Historia de literatura argentina Buenos Aires: CEAL 3 (1980), 98-113. También Charles Olson, poeta y ensayista emplea este término para la época después de 1875.

${ }^{6}$ En el término cultural resumimos otros fenómenos tales como la filosofía, sociología, arquitectura, film, teatro, danza, economía, ciencia etc.

${ }^{7}$ La discu sión de la postmodernidad se puede dividir en tres grupos: en uno que defiende la modemidad y rechaza la postmodernidad; en un segundo que defiende la postmodernidad y rechaza la modernidad y en un tercero que considera la postmodernidad como una evolución de la modernidad calificándola de una "modernidad postmoderna". Si se parte de la discusión histórica sobre el postmodernismo como lo ha planteado Rudolf Pannwitz ("Die Krisis der europäischen Kultur", en ibid.: Werke. Nürnberg 1917, Band II) o Arnold Toynbee (A Study of History, 1947) tenemos una alabanza al postmodernismo y una
} 
expresión el intento de la postmodernidad de poner en práctica en forma radical la actividad de la 'Verwindung' (reintegración/perlaboración) heideggeriana interpretada por Vattimo, como así la interpretación que le da Lyotard a los términos freudianos de 'Verarbeitung' (elaboración/ trabajo consciente) y 'Erinnerung' (memoria) ${ }^{8}$. La memoria abre la actividad, la elaboración trabaja con un material determinado y la perlaboración lo transforma en una nueva creación, donde lo antiguo y lo nuevo se funden en una unidad.

En la historia de la cultura aparece el término como tal por primera vez en 1917 con Pannwitz, luego lo encontramos en 1934 en una antología literaria de Onís y en 1947 en un libro de historiografía de Arnold Toynbee editado por C.D. Sommervell ${ }^{9}$.

Historia:

La concepción postmodernista de Pannwitz resulta de una diagnosis negativa de la época anterior (entre 1850-1917). El Postmodernismo es definido positivamente: éste es un fenómeno conservador, el hombre postmodernista es deportivo, nacionalista, militarista y religioso, se dirige contra la modernidad a la cual le es inherente el nihilismo y la decadencia.

En la discusión actual, que comienza con Gehlen en los años $50^{10}$, se analiza a la 'Posthistoria', respectivamente la Postmodernidad (después de la segunda guerra mundial) en forma negativa: como una época carente de innovaciones, en la cual las posibilidades de desarrollo histórico se han agotado, en donde no

condenación de la modernidad. En oposición a esta tendencia, sosteniendo exactamente lo contrario, se encuentra Arnold Gehlen (Über die kulturelle Kristallisation, en el mismo: Studien zur Anthropologie und Soziologie. Neuwied/Berlin 1963, 311-328 y Ende der Geschichte, en el mismo: Einblicke. Frankfurt a.M. 1975, 115-133. Con respecto a la arquitectura, literatura, teatro etc. v. nota 12,15,19y: Roberto Venturi: Complexity and Contradiction in Architecture. New York, 1966; Charles Jencks: The Language of Postmodern Architecture. New York, 1977; Susan Sontag: "Notes on Camp" and "One Culture and the New Sensibility", en Against Interpretation. New York, 1966; Styles on radical Will. New York, 1969; John Barth v. Nota 2; Leslie Fiedler: "The New Mutants", en Partisan Review, 1965; "Cross the Border -Close the Gap", en Playboy (December, 1969), nuevamente impreso en Marcus Cunliffe (Ed.): American Literature Since 1900. London 1975, 344-366; Jerome Klinkowitz: Literary Disruptions: The Making of a Post-Contemporary American Fiction. Urbana Ill, 1975. Un panorama general ofrece Wolfgang Welsch: Unsere postmoderne Moderne. Weinheim 1988; Wolfgang Welsch (Ed.): Wege aus der Moderne. Schlüsseltexte der Postmoderne-Diskussion. Weinheim, 1988.

${ }^{8}$ v. nota 11.

${ }^{9}$ El término ya se encontraba en 1870 en la pintura inglesa en oposición a la pintura impresionista.

${ }^{10}$ v. Nota 7 y del mismo autor: “Zeit-Bilder". Zur Soziologie und Ästhetik der modernen Malerei. Bonn 21965; v. también Norbert Bolz: "Die Zeit des Weltspiegels", en Ästhetik und Kommunikation 63 (1986): 113-120. 
existen actos creativos, sino formas meramente reproductoras de lo existente, que impiden la posibilidad de desarrollar nuevos valores, conceptos e ideales. Lo único que funciona es el aparato socio-económico de una siempre creciente sociedad de masa cuyos deseos y cuyas exigencias de consumo deben ser saciados. Demostraciones, protestas y otro tipo de actos subversivos son considerados ilusorios, como algo efimero, teatral, obsoleto y finalmente epigonal.

Somos, por el contrario, de opinión que la postmodernidad histórica comienza a desarrollarse durante los años 70 con los movimientos pacifistas, con el movimiento político-ecológico, con la perestroika, llegando a la culminación actual de su evolución con la desintegración de los sistemas estalinistas de Europa del este, evolución a la que seguirá, tarde o temprano, un radical cambio del sistema político-militar del oeste.

Sociología:

El término de postmodernidad se desarrolla en la sociología en EEUU a partir de 1958 con los trabajos de David Riesman (1958), se difunde luego con las investigaciones de Amitai Etzioni (1968), y la discusión llega a su culminación con los análisis de Daniel Bell (1973, 1976 ff.). En Europa se realiza el debate con Alain Touraine (1969) y Jean Baudrillard $(1971,1981)^{11}$.

En la socio-economía de Etzioni o Bell se argumenta en forma similar que en la historia. Se sostiene que el aparato socio-económico, que ha alcanzado una alta y diferenciada forma de producción, tiene la función de mantener el status $q u o$, lo cual reprime las actividades en otros sectores de la vida. Bell acepta, eso sí, en su diagnosis negativa del capitalismo norteamericano, que la cultura tiene una función subversiva, ya que ésta puede movilizar a las masas contra las exigencias de disciplina que implanta la producción capitalista.

Filosofía:

En este campo se inaugura el paradigma de la postmodernidad con la filosofía de Jean-François Lyotard (1979) y Gianni Vattimo (1980), y partiendo de estos dos autores se descubren retrospectivamente a Michel Foucault (1966), Jacques Derrida $(1967,1972)$ y Gilles Deleuze (1968) como fundadores de la filosofía postmoderna ${ }^{12}$.

${ }^{10}$ David Riesman: "Leisure and Work in Post-Industrial Society" en Eric Larrabee/Rolf' Meyersohn (Ed.): Mass Leisure. (Glencoe: Ill. 1958), 365-385; Amitai Etzioni: The Active Society. A Theory of Societal and Political Process. New York: 1968; Alain Touraine: La societé post-industrielle. Paris, 1969; Daniell Bell: The Coming of Post-Industrial Society. A Venture in Social Forecasting. New York, 1973; The Cultural Contradiction of Capitalism. New York, 1976; Jean Baudrillard: L'Echange symbolique et la mort. Paris, 1976. 12 Jean François Lyotard: La condition postmoderne. Rapport sur le savoir. Paris, 1979; Gianni Vattimo, Le avventure della differenza. Che cosa significa pensare dopo Nietzsche e Heidegger. Milano, 1980; Al di là del soggetto. Nietzsche, Heidegger e l'ermeneutica. 
La filosofía se despide del racionalismo y rigorismo cartesiano como así también de la metafísica. Ahora se da preferencia a la pluralidad de paradigmas concurrentes, a la diferencia, a la diseminación, a la heterogeneidad, a las distribuciones nómadas, a la "deconstrucción", a la interculturalidad e intertextualidad, al disenso y al antagonismo. La filosofía postmoderna es absolutamente abierta, y se entiende en parte como una relectura creativa y transformadora de discursos establecidos en la tradición. No solamente recurre a la tradición filosófica de la época moderna, sino a la tradición occidental en su totalidad, para fundar un nuevo discurso filosófico con las características mencionadas.

Arquitectura:

En el campo de la arquitectura y del diseño se inaugura la discusión pro o contra la postmodernidad con Nikolaus Pevsner (1966) y Roberto Venturi (1966), pero se llegará solamente a una difusión amplia en los años 70 (1977) con los trabajos de Charles Jencks (cuya teoría de la 'doble codificación' la toma evidentemente de Leslie Fiedler), y del alemán Heinrich Klotz (1985) ${ }^{13}$.

La arquitectura postmoderna (como así también el diseño) quiere crear una forma o estructura que sea capaz a la vez de considerar deseos particulares como generales eincorporar simultáneamente problemas arquitectónicos inmanentes, es decir, de incluir elementos locales/regionales y particulares combinados con formas históricas. La reintegración o el redescubrimiento del ornamento, de lo figural, del color local, en un sistema integrador caracterizan este movimiento

Milano, 1984; La fine della modernità. Milano, 1985; Michel Foucault: Le mots et les choses. Paris, 1966; Jacques Derrida: L'écriture de la difference. Paris, 1967 y "Le fins de l'homme", en Marges de la philosophie. Paris, 1972, 129-164; Gille Deleuze: Différence et répétition. Paris, 1968 y en colaboración con Félix Guattari: Rhizome. Paris, 1976.

${ }^{13}$ v.: Roberto Venturi: Complexity and Contradiction in Architecture. New York, 1966; Nikolaus Pevsner: "Architecture in Our Time. The Anti-Pioneers", en The Listener (29 december, 5 january 1976); Charles Jencks: The Language of Postmodern Architecture. New York,1977; Late Modern Architecture. New York, 1980; Post-Modernism. London, 1987; Jürgen Habermas: "Moderne und Postmoderne Architektur", en Der Architekt 2 (1982): 55-58 nuevamente impreso en el mismo: "Die Neue Übersichtlichkeit". Frankfurt am Main, 1985, 11-29; Daniel Bell: Immagini del Post-Moderno. Il dibattito sulla società post-industriale el'archittetura. Venezia, 1983; Jacques Derrida "Point de folie-maintenant l'architecture", en B. Tschumi (Ed.): La case vide. London, 1986 y en el mismo: "Psyché. Invention del'autre". Paris, 1987; Heinrich Klotz: Revision der Moderne. Postmoderne Architektur 1960-1980. München, 1984; Moderne und Postmoderne Architektur der Gegenwart 1960-1980. Braunschweig/Wiesbaden, 1987; "Moderne und Postmoderne", en Wolfgang Welsch(Ed.): Wegeaus der Moderne. Schlüsseltexte der Postmoderne-Diskussion. Weinheim, 1988, 99-109. Sin lugar a duda es Venturi uno de los más fascinantes arquitectos tanto en la teoría como en la práctica. 
arquitectónico, comolenguaje radicalmente plural, como comunicación, metáfora, que quiere o pretende provocar la fantasía del observador. La forma se acopla a un código 'socio-arquitectónico' con un metalenguaje lúdico narcisístico, con una finalidad explicatoria y descriptiva. La combinación de diversos materiales (mármol, granito, concreto armado, ladrillo, vidrio, acero y plástico), colores y formas (geométricas, griegas-romanas, clasicistas, barrocas, estilo décor, y Bauhaus etc.), como así también la recurrencia y retorno de elementos determinados (el agilón o frontispicio triangular griego, renacentista y clásico, puertas o entradas ovaladas con claraboyas, formas de naves de iglesias etc.), son algunas de las características de la arquitctura postmoderna que se encuentran en diversos países y regiones.

La arquitectura es considerada como un signo narrativo, argumentativo, icónico y estético de gran variedad, como una ficción, como puente entre ideas poéticas (entre la belleza decorativa) y su utilidad (funcionalidad), como puente entre lo antiguo y lo nuevo, como humor, ironía y parodia.

Arte:

Mientras que la práctica del arte postmoderno la inicia Andy Warhol en los años 60 con el Pop Art, y luego se desarrollan otras formas artísticas en EEUU y Europa tales como el fotorrealismo, el neoclasicismo durante los años 70 , se inicia la discusión teórica a partir de 1967. En 1980 se establece el término 'arte postmoderno' definitivamente en la crítica de $\operatorname{arte}^{14}$.

Los artistas postmodernos reintroducen lo figurativo, emplean una fuerte masa de colores, la subjetividad, la metáfora y la alegoría. Así como en otros campos de la cultura recurren a toda la tradición artística occidental (y no sólo a ésta). Encontramos temas, estilos, técnicas y formas conocidas, realizadas en forma de cita distanciadora o paródica o reintegrados en un nuevo concepto, provenientes del renacimiento, del clasicismo, del impresionismo, del cubismo, del surrealismo, expresionismo, futurismo, dadaísmo etc. Se caracteriza no a través de la exclusión, sino de la inclusión de lo uno y lo otro ${ }^{15}$.

${ }^{14}$ v. los trabajos de LeWitt: "Paragraphs on Conceptual Arts", en Artforum 5 (1967): 72 83, 0-9 (New York, 1969) and "Sentences on Conceptual Arts", en Art-Languages (England) 1,1 (1969); Brian O'Doherty: "What is Post-Modernism?", en Art in America 59 (1971): 19; Marshall Cohen (1971) y John T. Paoletti: "Art", en Stanley Trachtenberg (Ed.): The Postmodern Moment. A Handbook of Contemporary Innovation in the Arts. London, 1985, 53-80.

${ }^{15}$ Alguno de los pintores modernos serían: los americanos James Valerio, Bru no Civitico, John de Andrea; los italianos Carlo Maria Mariani, Lorenzo Bonechi, Franco Clementi, Sandro Chia, los alemanes Joseph Beuys y Christian Müller, el gru po de Berlín Occidental los "Nuevos Salvajes" (Neuen Wilden) Markus Lüpertz, Karl Horst, Dieter Hacker y Reiner Fettig; el ecuatoriano-berlinés Miguel Yaulema y el argentino Luis Suárez Jofré (San Juan) Argentina; cf. Heinrich Klotz: Die neuen Wilden. Stuttgart, 1987; Chales Jencks: Post-Modernism (Academy Editions) London, 1987; Klaus Honnef: Kunst der Gegenwart. Köln, 1988. 
Teatro:

Mientras que en todos los otros campos de la cultura, con la relativa excepción de la música, se inició una investigación científica de la postmodernidad, en el campo del teatro, se encontró ésta al comienzo en la crítica, llamémosla periodística. Con cierto retardo comenzó la crítica académica a ocuparse del campo en discusión.

La práctica del teatro postmoderno comienza en los años 60 con el Living Theatre, el Happening y el Open Theatre en New York. Tendremos que esperar, eso sí, a los años 70 y 80 , es decir, al teatro de B. Shepard, Robert Wilson, Peter Brook, Heiner Müller, Tankred Dorst, Jean-Marie Koltès, Alberto Kurapel, Ramón Griffero y Fernando de Tavira, para que éste llegase a su máximo desarrollo.

En 1985 aparecen los trabajos de June Schlueter y Erika Fischer-Lichte, que describen determinadas formas del teatro postmoderno. En 1989 propuse un modelo general para un amplio trato de las diversas manifestaciones postmodernas ${ }^{16}$.

El teatro postmoderno comienza en los años 70 y tiene las siguientes características: ambigüedad, discontinuidad, heterogeneidad, pluralismo, subversión, perversión, deformación, "deconstrucción", “decreación”, es antimimético y se resiste a la interpretación.

Se trata de un teatro en el cual se celebra el arte como ficción y el teatro como proceso, como performance, non-textualidad, donde el actor se transforma en el tema y personaje principal, donde el texto en el mejor de los casos es una mera base, en general carece éste de importancia. El texto es considerado como una forma autoritaria y arcaica. El texto es más bien un performance script. Laidea de performance toma una tercera posición, mediadora y subversiva en tre drama $\mathrm{y}$ teatro.

El teatro postmoderno se abre a todos los medios de comunicación (pluralidad de códigos: música, danza, luz, elementos olfativos), sin separarlos por rúbricas o géneros, y cualquier lugar pasa a ser lugar de teatro (cafés, garages, casas de

\footnotetext{
16 June Schlueter: "Theatre", en Stanley Trachtenberg (Ed.): The Postmodern Moment. A Handbook of ContemporaryInnovation in the Arts. London, 1985, 209-228; ErikaFischerLichte: Wilson/Heiner Müller "Civil Wars", en Historische und aktuelle Konzepte der Literaturge-schichtsschreibung. Akten des VII. Internationalen Germanisten-Kongresses Göttingen, 1985. Tübingen, 1986 vol. 11, 191-201; "Postmoderne Performance: Rückkehr zum rituellen Theater?", en Arcadia 22 (1987): 55-65; Un resumen de mi trabajo, "Hacia un modelo para el teatro-postmoderno" aparece en Gestos 6 (1990), la versión original, en F. de Toro/K.A. Blüher/A. de Toro (Eds.): Semiotica teatral y teatro latinoamericano (Galerna). Buenos Aires, 1990 y en Italia "Verso un modelo del teatro postmoderno", en Rivista Teatrale (Venezia) 1990.
} 
parqueo, off-Brodway, parques, iglesias, terrazas de edificios, Happening y Open Theatre $)^{17}$.

El actor se transforma en elemento-tema central, debe solamente representar a través de su gestualidad kinésica, a través de su actuar, de su percepción del mundo. En un teatro así concebido la palabra pierde su sentido, se actúa sin discurso, en base a meditación, gestualidad, ritmo, sonido, silencio, las acciones son instintivas, no se desprenden necesariamente de un entrenamiento. El teatro adquiere formas nihilistas, grotescas, llegando hasta el silencio (Robert Wilson), hasta el espacio vacío (Peter Brook).

El teatro postmoderno se resiste a la interpretación, el espectáculo no es más interpretable según parámetros semánticos tradicionales, los significados no son reducibles a una interpretación que dé un sentido profundo, un mensaje; el teatro postmoderno tiene elementos de la ciencia ficción, maneja, juega, cita el lenguaje cotidiano, ready mades combinados según una técnica de montaje donde los fonemas son destruidos y altamente recurrentes; fragmentación, montaje y repetición son principios comunes de la organización performativa del teatro postmoderno; intertextualidad: empleo de citas de otros autores y textos de diversas épocas o de textos propios, mas sin función ninguna; transformación del texto en un collage tonal, donde los signos se han despedido de su función denotativa, es decir, se han transformado en grafemas desemantizados; interculturalidad, es decir, la recepción de elementos de culturas extrañas en la propia, para producir un nuevo teatro.

El teatro postmoderno se manifiesta por lo menos en cuatro tipos de semiosis:

La primera es aquélla de la representación total y de la integración de todos los géneros artísticos, o por lo menos de una gran cantidad de éstos, que definimos como teatro plurimedial o interespectacular (aquí es posible la interpretación, pero no en forma tradicional de buscar un sentido alegórico, profundo; es decir, los signos están acoplados a significados tanto retóricos como kinésicos); ej.: Cosmopolitan Greetings de Ginsberg/Gruntz/Liebermann/Wilson y de Alberto Kurapel: Prometeo encadenado y Tres Performances.

La segunda es aquélla en que se evoca la representación de una acción o mejor dicho pseudo-acción narrativa, mas reducida radicalmente al gesto, que denominaremos teatrogestualo kinésico (lainterpretación tradicional semántica se hace prácticamente imposible, no ofrece casi significados, sino significantes): ej.: R. Wilson/T. Dorst: Parzival y Ramón Griffero: Historia de un galpón abandonado.

17 Con respecto al teatro latinoamericano podemos mencionar las obras de Alberto Kurapel: 3 Performances teatrales (Humanitas), Québec 1987; Prometeo encadenado (Humanitas), Québec, 1989; Ramón Griffero: Historia de un galpón abandonado. Espectáculo teatral (manuscrito); Luis de Tavira: la pasion de Pentesilea (Universidad Autonoma Metropolitana). México 1988 y Marco Antonio de la Parra: La secreta obscenidad de cada dia. Santiago/Chile: Planeta. Biblioteca del Sur, 1988. 
La tercera es aquélla en que se emplea el discurso, la fábula, el espacio y tiempo teatral, como pseudodiscurso, pseudofábula, pseudo-espacio y pseudotiempo. Lo hemos denominado teatro de deconstrucción. Se trata de una cita del teatro hablado, del teatro decadente, del teatro realista, del teatro, o mejor dicho, de la estética de fin de siècle, del teatro comprometido, del teatro pobre, del teatro social, del teatro del absurdo, del teatro historizante, sin ser nada de esto, sino citas, a través de las cuales constituye, por "deconstrucción", por montaje, su propio tipo de espectáculo. El espectador puede tratar de descodificar en forma semántica coherente el texto espectacular. Que se trata de un intertexto y de una nueva forma de discurso teatral lo vemos, p.e., en la fijación del texto, como texto dramático, por el contrario de Parzival y especialmente de Cosmopolitan Greetings; ej.: T. Dorst: Der Verbotene Garten, Jean-Marie Koltès: Dans la solitude des champs de coton y Luis de Tavira: La pasión de Pentesilea

La cuarta es aquélla que retoma la tradición del teatro hablado tradicional con todos aquellos elementos del teatro hablado, como personajes bien definidos (nombre completo, profesión, relaciones personales privadas y profesionales). La diferencia con el teatro tradicional mimético radica en la negación de un mensaje, en la absoluta anonimidad del discurso. A este teatro lo clasificamos como teatro restaurativo tradicionalista.

Otros campos de la postmodernidad, los cuales no podemos tratar en este lugar, serían la teología, la danza, la moda, la cocina y el diseño ${ }^{18}$.

\subsection{Periodización de la Postmodernidad}

Resumiendo, se puede fijar el comienzo de la Postmodernidad en 1960 con trabajos y obras de Sontag, Fiedler, Barth, Warhol, Sukenick, Mailer, Klinkowitz, Riesman, Gehlen, Etzioni, Touraine, Foucault, Derrida, Pevsner, Venturi etc. Esta primera etapa va hasta alrededor de 1970.

La segunda etapa se desarrolla entre 1970 y 1979, aquí podemos contar autores tales como Baudrillard, Bell, Jencks entre otros. La tercera etapa comienza más o menos en 1979 y es hoy vigente. Contamos aquía Robbe-Grillet, Duras, Eco, J. Marías, Montalbán, Azúa, Lyotard, Vattimo, Baudrillard, Bell, Klotz etc.

\section{POSTULADOS PRINCIPALES DE LA POSTMODERNIDAD LITERARIA}

Las características fundamentales de la postmodernidad literaria se pueden resumir, en un primer paso, bajo el término acuñado por Fiedler del 'anti-arte'

${ }_{18}$ Teología: Nathan Scott (1969) y en Marc C. Taylor (1984); "Danza: Michael Kirby: Introduction", en The Drama Review 19 (65-March, 1975): 3; Cf. Sally Banes: "Dance", en Stanley Trachtenberg (Ed.): The Postmodern Moment. A Handbook of Contemporary Innovation in the Arts. London 1985, 81-100; Cocina "La nueva cocina alemana" (Die neue Deutsche Küche), en Essen wie Gott in Deutschland. Hamburg 1987. 
y de la 'doble codificación'. Según éstos, se caracteriza la literatura (norteamericana) de la siguiente forma: es apocalíptica, antirracional, abierta y romántica, profética, desconfiada. Por otra parte, la crítica literaria no se debe concentrar ya más tan sólo en el análisis de la estructura de la obra, sino que debe describir el proceso de experimentación lectoral, se transforma ella misma en arte, emplea la obra de arte para producir otra.

La literatura postmoderna tiene la tarea de llenar vacíos entre los límites de la cultura establecida y canonizada y la subcultura, entre seriedad y risa, entre las belles lettres y el Pop Art, entre élite y cultura de masa, entre crítica y arte, entre artista y crítica, entre arte y público, entre profesionalismo y diletantismo y amateur, entre lo real y lo maravilloso/mito. La primacía de la fantasia debe imperar sobre la sobriedad. Los géneros bases de la postmodernidad son, según Fiedler, el Pop Art, la pornografía y el Western ${ }^{19}$.

En un segundo paso consideramos otros criterios no mencionados por Fiedler que incluirían otros países fuera de EEUU y que ampliarían el concepto de 'doble codificación' transformándolo en el de 'pluricodificación'; serían la 'deconstrucción', la intertextualidad', 'interculturalidad', la 'historización, la 'recepción/experiencia sensual- cognitiva del arte', la 'heterogeneidad', 'subjetividad', 'recreatividad', 'radical particularidad' o la 'diversidad' y por consecuencia la 'universalidad', como así también el 'minimalismo', la 'ironía', el 'humor', la 'fragmentación integrada' el 'collage' y un 'metadiscurso lúdico' ${ }^{20}$.

${ }^{19}$ Las tesis postmodernas de Fiedler representan una absolutización de una ideología, es decir, nos transmiten un ideal subjetivo del autor sobre la postmodernidad, o sobre como ésta debería ser. Por esto no se trata, en el caso de Fiedler, de una teoría de la cultura, la cual debería esforzarse por describir las diversas formas de la postmodernidad. Con esto crea Fiedler nuevos límites y cánones, lo cual está en abierta contradicción con la pluralidad propagada por él mismo, ya que debemos preguntarnos qué sucede con toda aquella literatura que no se ajusta a sus esquemas. La concepción de Fiedler describe solamente tres manifestaciones de la postmodernidad, en especial la norteamericana de los años 60, y allí aquélla que se denomina subcultura, cultura alternativa, PopArt. Fiedler nos da más bien un programa y no un término epocal o de estilo. De definitivo valor es el intento de Fiedler de cuestionar clasificaciones y definiciones de arte ya caducas, altamente elitistas burguesas y discriminantes, creando asi un espacio de reflexion legítima sobre las nuevas formas de arte y su crítica. Un semejante cambio se observa también en Roland Barthes, en Le plaisir du text. Paris, 1973 o en la obra de H.-R. Jauß: Ästhetische Erfahrung und Literarische Hermeneutik. München 1977, vol. I.

${ }^{20}$ El término 'metadiscurso' podría ser causa de confusion en la doble forma que lo u samos. Lo usamos, por una parte, como estructura universal dentro de aquella filosofía que desarrolla modelos explicativos generales y deriva leyes generales que, con éstos, pretenden lograr la verdad científica. Por otra parte, lo usamos como 'juego metadiscursivo', es decir, se refiere a indicaciones sobre los elementos y procedimientos u sados en la ficción, sea en una forma reflexiva como en el nouveau roman o en una forma lúdica ficcional, como en las novelas a describir, es decir, incorporado a la acción, constituyendo un todo y no una división entre objeto-lengua y metalengua. Otros autores que se han ocupado de la postmodernidad literaria serían: Ihab Hassan: The Dismemberment of Orpheus. Toward 
Como nos es imposible, por razones de espacio, explicar todos estos términos nos concentramos tan sólo en algunos de ellos. 'Deconstrucción'e 'intertextualidad' no son procedimientos literarios exclusivos de la postmodernidad, pero sí la forma de su empleo. Una obra deconstruccionista e intertextual es Don Quijote de Cervantes, que parte de modelos bien determinados como p.e. las novelas de caballería. Mientras en la obra de Cervantes el modelo que se parodia existe hasta el final de la obra, donde además se restaura el sistema mimético de la época (el Quijote reconoce su locura y rechaza los libros imitados), la referencia literaria en la postmodernidad es solamente citada al comienzo de la obra (=memoria), es elaborada de tal forma que desaparece en su nueva concretización (=perlaboración), como se da p.e. en los cuentos de Borges. La 'universalidad' no se realiza como en la modernidad a través de discursos, poéticas, estéticas o filosofías totalizantes y excluyentes de otras, sino a través de la pluralidad de códigos simultáneamente válidos. Bajo el término 'metadiscurso lúdico' entendemos aquella combinación sutil entre la narración de una historia y la descripción o el juego con los procedimientos narrativos empleados para narrarla. En el epígrafe sobre Borges, citado al comienzo del trabajo, el narrador describe la obra de Ts'ui Pên que tiene el mismo título del cuento de Borges en el cual está insertada la novela, es decir, Ts'ui Pên es Borges, y con esto está describiendo su propia escritura. Por otra parte, es este pasaje una síntesis pionera de la teoría del rhizoma de Deleuze/Guattari, pero no en una forma teórica, sino en un juego literario.

La postmodernidad no se deja definir como la modernidad a través de la exclusión y a través de oposiciones, sino de la inclusión. Las oposiciones no representan incompatibilidades, sino posibilidades de nuevas manifestaciones.

a Postmodern Literature. Oxford:University Press, 1971(UB); "Postmodernism", enNew Literary History 3,1 (1971): 5-30; "Pluralism in Postmodern Perspective", en Critical Inquiry 12 (1985/86): 503-520; "Postmoderne heute", en W.Welsch(Ed.):Wegeaus der Postmoderne. Schlüsseltexte der Postmoderne-Diskussion. Weinheim, 1988, 47-56; Hoffman, G. (Ed.): Der zeitgenössische amerikanische Roman. München, 1988, vol. I-III; G. Hoffmann/A. Hornung/R. Kunow: “'Modern', Postmodern' and 'Contemporary' as Criteria for the Analysis of 20th Century Literature", en Amerika Studien 22,1, (1977): 19-46; Michael Köhler: "Postmodernismus: Ein begrifflicher Uberblick", en Amerika Studien 22, 1(1977): 8-18; J. Peper: "Postmodernismus: Unitary Sensibility (Von der geschichtlichen Ordnung zum synchron-environmentalen System)", en Amerika Studien 22,1 (1977): 6589; Andreas Huyssen: "The Search for Tradition. Avantgarde and Post-modernism in the 1970ths", en New German Critique 22 (1981): 23-40; ibid.: "Mapping the Postmodern", en New German Critique 33 (1984): 5-52; Julia Kristeva: 'Postmodernism?', en Harry R. Garvin (Ed.): Romanticism, Modernism, Postmodernism. Lewisburg (Penn.) 1980, 136141; Douwe W. Fokkema: Literary History, Modernism and Postmodernism. Amsterdam/ Philadelphia, 1984; Stanley Trachtenberg (Ed.): The Postmodern Moment. A Handbook of Contemporary Innovation in the Arts. London, 1985; A. Kibedi Varga: Litterature et postmodernité. Groningen, 1986; Theo D'haen/Hans Bertens: Postmodern Fiction in Europe and the Americas. Amsterdam, 1988; Nelly Richard: La estratificacion de los márgenes. Santiago/Chile 1989. 


\section{LA POSTMODERNIDAD LITERARIA EN LATINOAMERICA: LA NOVELA}

En un comienzo parece altamente dificil hablar de la postmodernidad en Latinoamérica ya que, como hemos visto, se trata de un fenómeno global que tiene su origen fuera del continente latinoamericano y, como fenómeno global, no comparte una gran cantidad de características, especialmente con lo que se refiere al aspecto socio-económico, político y científico. Es precisamente esta globalidad lo que produce en Latinomérica, en principio, una fuerte actitud de rechazo.

Pero existen otras razones: una determinada corriente en Latinoamérica sigue no queriendo aceptar aquello que Borges formulaba hace ya decenios: que una gran parte de la cultura latinoamericana es parte indivisible de la cultura occidental.

La opinión de Borges se puede reformular constatando que Latinoamérica goza del privilegio de pertenecer a dos o más tipos de culturas.

Considerando una serie de aspectos ideológicos, sociales, étnicos y otros, sostenemos que Latinoamérica, constituida por un desgarrado sincretismo, se caracteriza por una gran disociación a todo nivel: el nivel cultural no tiene correspondencia con el económico, ni el económico con el social, ni éstos con el político. Me refiero a que mientras Latinoamérica ya a comienzos de siglogoza de una gran poesía, y a más tardar en los años 50 se desarrolla una hiperactividad ensayística y novelística, permanecen los campos de la ciencia, economía, tecnología, industria y política en el subdesarrollo o en un modesto desarrollo; naturalmente que no olvidamos excepciones bien conocidas.

Se puede concluir, sin caer en la exageración que gran parte del continente no entró a la modernidad, y a los pocos países que entraron, en cierta medida el esfuerzo de modernización los condujo a la bancarrota, por lo menos momentáneamente.

A pesar de lo dicho podemos, sin ningún problema, hablar de la modernidad literaria latinoamericana que comienza por allí en 1888 y se desarrolla en varias etapas hasta principio de los años $60^{21}$, y si aceptamosloexpuesto, pues, estaremos obligados a denominar y describir aquello que sucede en los años posteriores con otro término (a no ser que se quiera petrificar la modernidad), y esto es con el de postmodernidad.

Esta propuesta que quiere incluir la disociación descrita no tan sólo para la modernidad, sino a la vez para la postmodernidad, persigue dos finalidades: una es el evitar que Latinoamérica quede fuera de la discusión general de un fenómeno de semejante envergadura, como ha sucedido ya tantas veces en la

${ }^{21}$ La primera etapa iría de 1888 (Azul) hasta 1925, la segunda de 1925 (Residencia en la tierra) hasta alrededor de 1955 y la tencera de 1955 (El Acoso, Pedro Páramo) hasta el comienzo de los años 60 . 
historia de la cultura, la otra es el describir el aporte propio de Latinoamérica a la postmodernidad ${ }^{22}$.

No he compartido jamás la opinión de que Latinoamérica sea "diferente" y por esto no pueda estar englobada en fenómenos universales generales. Latinoamérica es tan diferente de USA o de Europa como lo es EEUU de Europa, Italia de Alemania y España de Francia, mas no por esto, estos continentes y países se excluyen de servirse de toda la riqueza cultural de los vecinos. La famosa identidad y la acusada y demonizada hegemonía cultural bajo la que sufre presuntamente Latinoamérica son dos caras de un mismo mito, que ha postrado a Latinoamérica, por períodos, al provincialismo cultural. La historia cultural de Latinoamérica ha demostrado ya hace decenios la falacia de esta posición: Neruda, poeta universal, sale de la provincia, de un país subdesarrollado; Roa Bastos proviene de un feudo, Carpentier del azúcar, García Márquez de la superstición, Vargas Llosa de un país culturalmente descastado. Mas todos fueron y son autores latinoamericanos en la medida en que supieron emplear la cultura universal como suya, y con esto no perdieron su identidad, sino que la crearon. La identidad de un Borges, que vivió casi toda su vida en Buenos Aires (sostengo que Borges vivió más tiempo en B.A. que cualquiera de los autores actuales ha podido vivir en sus países de origen) es inconfundible a través de su escritura. El discurso artístico es lo que da identidad a una cultura y no solamente el lugar de origen.

Frente a este cuadro partimos de la base que en Latinoamérica existe naturalmente una postmodernidad, la cual entramos a describir en el campo de la novela.

\footnotetext{
${ }^{22}$ El problema fundamental de Latinoamerica radica en los escasos medios de publicación. Son práctimante inexistentes los fondos nacionales que permitan subvencionar libros en editoriales con distribución internacional como es lo usual en Europa y Norteamérica. El fenómeno se ha discutido desde mediados de los 80 , primeramente en sociología, con una carga ideológica muy grande, y en arquitectura; v. entre otros Maurizio Ferraris: "Postmoderno", en Punto de Vista 21 (Buenos Aires) (1984); 4-5 (1986); 31 (1987); 33 (1988);Revista First 19 (1988);29 (1989); Revista de Estética (Centro de Arte y Comunicación de Buenos Aires) 5-6 (1987) 32-37; Revista Universitaria (Universidad Católica de Chile) 22 (1987) 38-43; Pedro Morandé: "La cultura como experiencia o como ideologia", en Revista Universitaria 22 (Universidad Cat6lica de Chile, 1987): 44-48; Fernando Pérez: "La compleja superación de la sensibilidad y el ideal moderno en el terreno de la arquitectura", en Revista Universitaria 22 (Universidad Cat6lica de Chile, 1987): 49-55; Nicolás Casullo (Ed.): El debate modernidad/postmodernidad. Buenos Aires, 1988; Imágenes desconocidas. La modernidad en la encrucijada postmoderna. Buenos Aires, 1988; Postmodernidad. Buenos Aires, 1988; Rosa María Ravera: Estética y semiótica. Rosario, 1988; Pablo Oyarzún: La polémica sobre lo moderno y lo postmoderno, en Nelly Richard: La estratificacion de los margenes. Sobre arte, cultura y politicas. Santiago/ Chile, 1989.
} 


\subsection{J.L. Borges o el comienzo de la postmodernidad}

J.L. Borges inaugura con Ficciones (1939-1944) la postmodernidad, no solamente en Latinoamérica, sino en general. Lo dicho podría ser interpretado como una contradicción, ya que hemos indicado que la postmodernidad es un fenómeno que se origina en EEUU y en los años 60 . Si hubiese una semejante contradicción, ésta sería de carácter cronológico, no de carácter sistemático. A la obra de J. L. Borges le ha sucedido aquello que han experimentado muchas obras de la literatura universal: su discurso no se había podido fijar históricamente, ni en lo que podríamos llamar la 'alta modernidad' ovanguardia, ni en la 'modernidad tardía', es decir, en aquella literatura que aparece en los años $50^{23}$, por la sencilla razón de que la escritura de Borges se encontraba ya en el último tercio del siglo XX. Este es también el lugar donde radica la incomprensión que produjo su obra por largo tiempo tanto en Latinoamérica como en Europa. Borges abrió, dentro del paradigma de la modernidad, aquél de la postmodernidad, que atrajo la atención de algunos círculos tanto filosóficos como literarios, como aquél del nouveau roman y del post-estructuralismo ${ }^{24}$.

¿Cuáles son precisamente las características del discurso postmoderno borgesiano?

${ }^{23}$ La modernidad europea puede ser periodizada de la siguiente forma: 1) la modernidad joven que va de Baudelaire, pasando por Flaubert y Zola hasta comienzos del siglo XX (1850-ca.1910/20; 2) de Proust, pasando por Kafka, Woolf, Joyce, Dos Passos hasta Faulkner (1910/20-1939); 3) de 1955, hasta comienzos de los años 60.

${ }^{24} \mathrm{La}$ deu da del nouveau roman con Borges, a quien ya se lo conocía en Francia a más tardar desde 1955, es considerable. Un dato importante es que Ficciones de Borges fue traducida por P. Verdevoye al francés en 1951. Fuera de eso se le dedicaron a su obra entre 1923 y 1955, es decir, antes que se difundiera el nouveau roman, una serie de trabajos realizados por autores franceses por lo general en francés y/o en Francia por importantes autores en conocidísimas revistas literarias y periódicos de amplia difusión, que también luego se ocupan del nouveau roman, de tal manera que resulta sorprendente la amnesia de los autores franceses y de la crítica francesa. Citamos sólo algunos de los trabajos aludidos: R.M.Albérès: “J.L. Borges ou les deux bouts du monde”, Affinités II, 7 (Abril 1953): 84,85,92; P. Bénichou: “Kublai Khan, Coleridge y Borges”, en Sur 236 (septiembre-octubre 1955): 57-61; M. Brion: "D'un autre hémisphère", en Le Monde (26 mars 1952); idem: "J.L. Borges et ses Labyrinthes", en Le Monde (18 août 1954); R. Caillois: "Soldat de la liberte", en Opera (30 janvier 1952); M. Carrouges: "Le gai savoir de Jorge Luis Borges", en Preuves 13(1952): 47-49; M. Daireaux: "Littérature hispano-américaine", en Ed. Kra, Panoramas des Littératures Contemporaines; Etiemble: "Un homme à tuer: Jorge Luis Borges, cosmopolite", en Les Temps Modernes 83 (septembre 1952): 512-526; A. Hoog: "Au delà de l'enigme: Jorge Luis Borges: Ficciones", en Carrefour 26 mars, 1952; R. Kemp: "La vie des livres. Vérités et Fictions", en Les Nouvelles Litteraires 20 (mars 1952); M. Nadeau: "Un écrivain déroutant et savoureux: J.L. Borges", en L'Observateur 94 (28 février 1952); G. Pillement: "Fervor de Buenos Aires", en Revue de l'Amérique Latine II, 6 (nov. 1923); R.N.: ¿Avez-vous lu Borges?, en Opéra 346 (23 février-4 mars 1952): 3. 
a) El discurso literario: juego intertextual "deconstruccionista", cita de otros autores de literatura ficcional y de textos ficcionales anónimos (Homero, Shakespeare, Cervantes, Flaubert, Joyce, Valéry, Chesterton, Kafka, Las 1001 noches, D'Annunzio, Agatha Christie), tanto de la cultura occidental como de otros sistemas;

b) El discurso literario ficcional fantástico ("El Aleph", "Tlön, Ubqar Orbis Tertius", "El Zahir", "La lotería de Babilonia", "El inmortal");

c) El discurso filosófico, metafísico, teoría de la ciencia, lógica (cita y empleo de filósofos, como Lull, Leibniz, Descartes, Berkeley, Hegel, Spengler, Kant);

d) El discurso teológico (San Agustín y debates sobre la existencia de Dios y de la estructura del mundo);

e) El discurso religioso/místico ("Los teólogos", "La escritura del dios");

f) El discurso filológico ("La busca de Averroes", cita de la Revista de Filología Española o de la $N R F$, enciclopedias, mapas etc.);

g) El discurso genérico: ensayo, análisis literario ("Examen de la obra de Herbert Quain");

h) El discurso detectivesco ("Abenjacán el Bojari muerto en su laberinto", "La espera", "El hombre en el umbral", "El jardín de senderos que se bifurcan", "La muerte y la brújula");

i) El discurso de aventuras ("El sur", "El fin", Abenjacán el Bojari");

j) El discurso (pseudo-)realista ("El sur", "El fin");

k) El discurso (pseudo-)cotidiano (cita de periódicos, revistas);

1)El metadiscurso ("Pierre Menard, autor del Quijote", "El Aleph"; "El inmortal", "La casa de Asterión", "La otra muerte");

m) El discurso narrativo paródico, humor, ironía.

n) El discurso histórico;

La narración misma se caracteriza como sigue:

a) Tono científico (mimesis científica, mas aquí como juego: superación del realismo decimonónico que era una mimesis científica mas tomada en serio): citas de revistas filológicas, textos y autores existentes y no existentes;

b) Autor omnisciente;

c) Fábula consistente con una acción, lugares tiempos y personajes bien delineados, mas luego "deconstrucción", máscara, disolución, difusión;

d) Ambigüedad, resistencia a la interpretación;

e) Alusión, sin solución;

f) "Deconstrucción" delo dicho, constitución de significados y su "deconstrucción" en significantes;

g) Alusión autobiográfica;

h) Mezcla absoluta de realidad y ficción, sin implicaciones ontológicas;

i) Reflexión sobre la escritura y lo narrado;

j) Pseudo-localismo (pseudo-neocostumbrismo/pseudo-realismo);

k) Mito entre historia y lenguaje: semiotización, disgregación diseminación del mito; 
1) Disolución del narrador en tercera persona que se pierde a través de las contradicciones en su discurso, en primera persona: tiene muchas identidades y ninguna, es narrador y personaje a la vez, en relación consigo mismo o disociado;

m) Colectividad y repetición: la disolución del creador y del mito del genio; el texto como origen de la productividad;

n) Lector como activo co-autor: descodificación, "deconstrucción" de segundo grado.

\subsubsection{La Biblioteca de Babel}

En "La Biblioteca de Babel" se puede demostrar en forma ejemplar algunas de las características mencionadas.

El narrador incita a sus personajes y al lector a una búsqueda de significantes dentro de la cual la búsqueda misma, el camino a recorrer, es lo más importante, ya que, si se encuentran significantes, éstos permanecen herméticos. El bibliotecario babilónico se encuentra a la búsqueda del catálogo de los catálogos; es decir, no de un significado, sino de un principio de orden de la biblioteca, que es el equivalente con el universo, esto es, coon el lenguaje. En su búsqueda fracasa el bibliotecario, lo cual equivale en otros cuentos con la imposibilidad de descodificar el secreto que encierra un significado ${ }^{25}$.

Borges niega la solución, y si se vislumbra alguna, es ésta tan arbitraria y contra la lógica del lenguaje que se puede prescindir de ella, como p.e. en "Tlön, Uqbar, Orbis Tertius", donde las cadenas sintagmáticas del lenguaje son deconstruidas. Por ejemplo: no hay una palabra que corresponda a la palabra luna, pero hay un verbo que sería en español lunecer o lunar. Surgió la luna sobre el río se dice hlör u fang axaxaxas mlö o sea en su orden: hacia arriba (upward) detrás duradero-fluir luneció. (Xul Solar traduce con brevedad: upa tras perfluyue lunó. Upward, behind the onstreaming it mooned) [...] No se dice luna: se dice aéreo-claro sobre oscuro-redondo o naranjado-tenue- del cielo.

Los objetos son creados a través del lenguaje, a través de la fuerza de la fantasía como los "hrönir", en "Tlön, Uqbar, Orbis Tertius".

\subsubsection{Undr}

En "Undr" la búsqueda es mucho más radical aún que en el cuento anterior. Se tematiza el fracaso, la repetición de lo mismo, el Apocalipsis. Cuando Ulf Sigurdarson después de muchas aventuras regresa al pueblo de los ataúdes para descifrar el secreto por él buscado, le dicen que éste ha sido revelado y se llama Undr:

${ }^{25}$ P. e. en "La escritura del dios". Si se descubre/denomina el enigma, éste no es descifrable como en "El Aleph" o "Undr". 


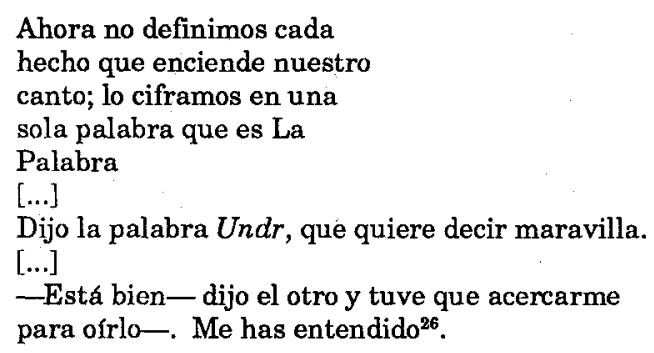

Con lo cual no se descifra nada, sino se mantiene el hermetismo.

\subsubsection{Pierre Menard, autor del Quijote}

En Ficciones (1944), precisamente en "Pierre Menard, autor del Quijote" (1939), J.L. Borges nos descubre la anticipación por analogía entre su discurso y la teoría de la recepción, la lingüística del texto, la semiótica, la deconstrucción, la intertextualidad y el palimpsesto.

La finalidad perseguida por Pierre Menard era la de escribir un segundo Don Quijote que estuviese en acuerdo con la época de su momento de producción. Menard no actualiza al héroe en forma recreativa, es decir, transformándolo en un personaje similar en relación con la época contemporánea o en forma simplista, es decir, poniéndolo en un medio extraño a éste, p.e. en la Wall Street, sino que lo copia letra por letra, línea por línea ${ }^{27}$.

Este cuento problematiza el fenómeno de la identidad/similitud y la diferencia, es una mezcla de ficción y ensayo científico, de ciencia literaria y fantasía.

Al nivel del significante es el texto de Menard idéntico con el de Cervantes, pero a un nivel semántico-pragmático se diferencia plenamente de éste, ya que los sintagmas transpuestos en el tiempo han cambiado sus significados. Nos encontramos no con un palimpsesto semántico (=cambio de lexemas), sino con un palimpsesto pragmático (=permanencia de lexemas, transposición en el tiempo). Como ejemplo da Borges el capítulo I, 9 del Don Quijote:

... cosa mal hecha y peor pensada, habiendo y debiendo ser los historiadores puntuales, verdaderos y no nada apasionados, y que ni el interés ni el miedo, el

26 J.L. Borges, “Undr”, en El libro de arena, Madrid: Alianza, 1975 (1986), (1975). 66, 68.(7)

${ }^{27}$ Cf. Alfred J. MacAdam/Flora H. Schiminovich: Appendix II. "Latin American Literature and the Postmodern Era", en Stanley Trachtenberg (Ed.): The Postmodern Moment. A Handbook of Contemporary Innovation in the Arts. London 1985, 251-262 y Hans Robert Jau ß: Die Theorie der Rezeption-Rückschau auf ihre unerkannte Vorgeschichte (Konstanzer Universitätsreden 166). Konstanz 1987, 30ff. 
rancor ni la afición, no les hagan torcer el camino de la verdad, cuya madre es la historia, emula del tiempo, deposito de las acciones, testigo de lo pasado, ejemplo y aviso de lo presente, advertencia de lo por venir ${ }^{28}$.

Esta frase que en tiempos de Cervantes -como dice el narrador-era una expresión retórica para el elogio de la historia, adquiere otra cualidad en la época de Menard, que es un contemporáneo de William James, el cual -como sabemos- relativiza en su Pragmatism (1907) el concepto metafísico de la verdad, proponiendo la fórmula: verdadero es aquello que se confirma.

Desde el siglo XIX la historia adquiere un estatus privilegiado, lo cual vale aún más para el sigloXX: ésta no es solamente una disciplina que investiga una parte de la realidad, sino que es la fuente para la explicación del comportamiento, y con esto del origen de la vida y de la realidad. Frente a esta concepción se puede explicar - como también asegura el narrador- el fracaso de Flaubert en Salammbô, el cual trató de reconstruir el pasado, un propósito que el autor abandonará luego en Bouvard et Pécuchet.

"Pierre Menard" es uno de los textos más representativos del discurso borgeano en cuanto éste sostiene que la realidad, y con esto nosotros mismos, somos resultado del lenguaje, y así declara que la metafísica (ila ciencia de las últimas razones!) es una rama de la literatura fantástica ${ }^{29}$. El postulado no es ya más cogito ergo sum, sino "escribo luego existo".

Esta actitud es postmoderna, en cuanto Borges no le atribuye a la tradicional oposición entre realidad y ficción una cualidad ontológica. Ambas dimensiones poseen el mismo estatus, lo cual se comienza a articular en la nueva novela a partir de los años 50 en lo 'real maravilloso' o el 'realismo mágico' o 'mítico', como así también en la novela norteamericana del los años 60 en la llamada 'surfiction'so.

Apocalipsis en el sentido de repetición, de la negación del movimiento lineal, en el sentido de desenmascarar la existencia del apocalipsis cristiano (Derrida ${ }^{31}$ ) se manifiesta en que la realidad se descubre como ficción a través de la recurrencia de lo dicho o escrito (='Negación de la originalidad, del novismo vs. acentuación de la intertextualidad y deconstrucción'). Para evitar la repetición y nuevas especulaciones de lo escrito, para evitar eso que él mismo ha emprendido, destruye Menard su manuscrito. Esta actitud estético-existencial es retomada y radicalizada por Italo Calvino en Se una notte d'inverno un viaggiatore $^{32}$. Borges pone en claro que un texto no se puede entender aislado,

${ }^{28}$ Cervantes: Don Quijote de la Mancha (Espasa Calpe). Madrid, 1975, 222.

29 "Tlön, Uqbar, Orbis Tertius", en Ficciones Madrid,(Emencé/Alianza) 1972, 24.

${ }^{30}$ Raymond Federman (Ed.): Surfiction, Fiction ... Now and Tomorrow. Chicago, 1974.

${ }^{31}$ Jacques Derrida: "Point de folie-maintenant l'architecture", en B. Tschumi (Ed.): La case vide. London,1986 y el mismo en Psyché. Invention del'autre. Paris, 1987.

${ }^{32}$ Torino: Einaudi, 1979. 
sino solamente en relación con otros textos, lo cual pone de manifiesto en sus comentarios sobre Kafka: un autor no necesita conocer a sus antecesores para escribir como lo hace, sino que, por el contrario, partiendo de un autor contemporáneo se descubren los pasados ${ }^{33}$. De esta forma se produce una disolución del Yo que pasa a ser una voz colectiva, que se manifiesta solamente en la palabra. Al fin queda solamente el lenguaje, el juego agonal lúdico que se impone y no el Yo (Lyotard $\left.\mathrm{d}^{34}\right)$. Se pasa del autor como productor, al texto como productor, lo cual implica que todo autor es primeramente un lector, se pasa de la presunta originalidad al palimpsesto.

A pesar de ser J.L. Borges el primer autor postmoderno, su discurso no desenlazó un paradigma, sino, como hemos indicado, éste se constituye en los años 60. Debemos indicar que la obra de Borges se descubre como postmoderna partiendo de una perspectiva retrospectiva, así como Kafka se puede comprender a través de Borges (según éste mismo), así se entiende la postmodernidad por medio de Borges, de la misma forma como partiendo de Lyotard y Vattimo, se descubre a Foucault y Derrida.

\subsection{La novela postmoderna latinoamericana}

A continuación quisiéramos, partiendo de las categorias expuestas más arriba, proponer algunas ideas para el trato de la novela latinoamericana bajo un punto de vista postmoderno. Esta propuesta quiere ser más una motivación que un modelo para reflexionar sobre el fenónomeno en cuestión ${ }^{35}$.

${ }^{33}$ v.J.L. Borges: “Kafka y sus precursores (1960)", en Otras Inquisiciones (Alianza/Emecé). Buenos Aires/Madrid 1985, S. 107ff.; Cf. Eberhard Geisler: "Paradox und Metapher. Zu Borges' Kafka-Rezeption”, en Romanische Zeitschrift für Literaturgeschichte 1/2 (1986): 219-243.

${ }^{34}$ F. Lyotard: La condition postmoderne. Paris, 1979; Le Différend. Paris: Minuit, 1983. งs Algunos críticos partiendo del 'realismo mágico', de la pluralidad y de la estructura abierta de la nueva novela tienden a calificar la novela latinoamericana casi en su totalidad y si no de 1955, por lo menos de 1965 en adelante de postmoderna. Esta tendencia se descubre como un ermor, ya que no todas las novelas del periodo mencionado tienen las características mencionadas tales como intertextualidad, deconstrucción, pluralidad, juego metatextual, parodia, ironia, humor, coloquialidad, discurso de subcultura etc. Cuando se sostiene que Cien años de soledad es una novela postmoderna porque allí domina el principio del 'realismo mágico', porque existe un narrador omnisciente, una historia coherente, luego tendríamos que denominar también no solamente al Don Quijote, sino la Illada y la Odisea como tales. Lo mismo vale para los términos de 'deconstrucción' e 'intertextualidad' que son patrimonio de la literatura desde hace siglos. Gran parte de la nueva novela pertenece a lo que hemos llamado 'modernidad tardía', esto es, a aquella novela que va de 1955 a comienzos de los 60, también en Europa y que en Latinoamérica se extiende hasta los años 70, y que se caracteriza por la renovación, el experimento, la focalización de la historia y su traspaso a la conciencia de los personajes (stream of consciousnes), donde se problematiza la mimesis y se trata de encontrar una fórmula 
4.2.1 La novela del 'metadiscurso, de la intertextualidad, deconstrucción e introspección': J. Cortazar, Rayuela (1963)

Rayuela es una novela con una estructura particular en cuanto el autor le ofrece al lector tres posibles lecturas ${ }^{36}$. La primera consiste en leer el texto tal como está impreso, es decir, en forma lineal, sin saltos; en la segunda se propone leer los capítulos 1-56 y dejar los restantes fuera; la tercera, que es recomendada expressis verbis por el autor, ofrece un orden determinado de lectura que parte del capítulo 73 y luego se salta al capítulo siguiente, indicando al fin de cada capítulo respectivo, etc. Esta lectura es compleja, pero encierra la clave de la comprensión del texto.

Rayuela se caracteriza también por su ironía, su humor, por su carácter lúdico, como así también por su variedad de discursos, tales como el parodístico, el deconstruccionista, el intertextual (frente a la novela realista histórica, cap. 34), el filosófico, el existencialista, el metalingüístico (con respecto a la teorfa de la novela, en especial en la parte III, pero se encuentra prácticamente en toda la novela), y finalmente la representación de la heterogeneidad ('Paris vs. Buenos Aires').

Fragmentación y diversidad tanto al nivel del discurso como de la segmentación tipográfica de la novela producen una estructura abierta y nómada.

La variedad se concretiza también en los campos tratados, el mítico (Maga), en el del pensamiento y del conocimiento, en el de la teoría de la cultura y filosofía (Oliveira/Paris), en el del amor y la pasión.

Que Rayuela constituye un puntofundamental de cambioen la nueva novela, lo habia ya hace algún tiempo constatado Leo Pollmann:

Rayuela de Cortazar [...] nos conduce al año 1963, en el cual la Nueva Novela latinoamericana se encuentra en un momento de cambio [...], que se puede

lingüística y narrativa propia. En los años 60 se comienza paralelamente a desarrollar la novela postmoderna, que por otra parte no es precisamente equivalente a lo que se está llamando 'novela del postboom'; al respecto v. Alfred J.MacAdam/Flora H. Schiminovich: Appendix II. "Latin American Literature and the Postmodern Era", en Stanley Trachtenberg(Ed.): The Postmodern Moment. A Handbook of Contemporary Innovation in the Arts. London, 1985, 251-262. En una forma similarmente eclectica argumenta Brian McHalle en Postmodernist Fiction. New York/London, 1987, 12-27, el cual califica de postmodernos a cualquier cantidad de autores, sin darnos los más mínimos criterios clasificatorios; tambien John Barth en "The Literature of Replenishment", The Friday Book: Essays and Other Nonfiction. New York, 1984, 193-206, trata de calificar algunos autores latinoamericanos de postmodernos, lo cual ha sido refutado por $\mathrm{O}$. Paz y Julio Ortega; v. "Postmodernisme in Latin America", en Th. D'haen and H. Bertens (Ed.): Postmodern Fiction in Europe and the Americas. Amsterdam/Antwerpen, 1988, 193-208. ${ }^{36}$ Capitulos para leer: 1-56 y capitulos prescindibles: $57-121$. 
considerar como una nueva tesis [...]. La estructura de Rayuela se encuentra en el debate con el pensamiento europeo, con la tentación de la monocausalidad o con la moderada verticalidad del tornillo. [Cortazar cre6] la obra del Sic et Non, de la especificidad latinoamericana de lo uno y lo otro ${ }^{37}$.

\subsubsection{La novela del discurso de masas: 1968 ...}

A este grupo pertenecen novelas tales como las de Manuel Puig La traición de Rita Hayworth (1968), Boquitas pintadas (1969), The Buenos Aires Affair (1973), El beso de la mujer araña (1976), Mario Vargas Llosa La tía Julia y el escribidor (1977), Gabriel García Márquez El amor en los tiempos de cólera (1987) y Antonio Skármeta Matchball (1988).

Como ejemplo quisieramos comentar la novela de Mario Vargas Llosa La tía Julia yelescribidor, que está constituida por diversas "historias" organizadas según el método de series de radio novelas.

Al comienzo tienen todas las historias el mismo estatus narrativo, es decir, el lector implícito cree que lo narrado realmente tiene lugar directamente en la ficción. La única diferencia entre las diversas historias radica en el hecho de que, mientras todas ellas tienen diverso contenido, son narradas por un narrador en tercera persona y su fin permanece abierto con la pregunta del narrador de cómo sería su final; hay otra que siempre retorna con un yonarrador y que trata de la relación y vida de Mario y la tía Julia.

En el transcurso de la narración el lector se da cuenta de que la narración en primera persona constituye el marco narrativo general, y las historias en tercera persona son parte del marco interno, como en la 1001 Noches $^{38}$, con lo cual tenemos más bien la estructura de una novela corta/cuento que de una novela. Esta estructura corresponde al estatus de las diversas historias que son la consecuencia de las radio-novelas escritas por el boliviano Pedro Camacho para la Radio Central, es decir, escritas por un personaje que pertenece al marco narrativo general y que es calificado como "escritor decimonónico", con lo cual se establece una referencia con las novelas en episodios que se ponen de moda en los periódicos del siglo XIX en adelante.

${ }^{37}$ L. Pollmann: DerNeu Roman in Frankreich und Lateinamerika. Stuttgart 1968, S.211212 u.ff.. y 215. Traducción.: “Cortázars Rayuela [...] führt uns [...] ins Jahr 1963, in dem der Neue Roman Lateinamerikas an einer Wende steht [...], die auch als Ankündigung einer neuen These [...] gewertet werden kann. [...]. Die Struktur von Rayuela steht also in der Auseinandersetzung mit dem europäischen Denken, mit der Versuchung zur Monokausalität oder auch nur zur gemäßigten Vertikalität der Schraube. [Cortazar schuf] dieses Werk des strukturellen Sic et Non, des so spezifisch lateinamerikanischen Sowohl als auch". Claro está que Pollmann considera esta novela, y las de este período, como culminación de la nueva novela in sensu strictus (a diferencia nuestra que la ubicamos desde El Acoso y Pédro Páramo.

${ }^{38}$ El marco general esta constituido por cifras impares $1,3,5$ etc. y entre éstas se encuentran las radio-novelas. 
Mientras a continuación las diversas historias permanecen independientes las unas de las otras, comienzan a desdibujarse los límites entre las historias singulares como resultado de una creciente pérdida de la memoria de Camacho, que se produce por su excesiva y obsesionada cantidad de trabajo. En un comienzo confunde éste los nombres y roles de los personajes pertenecientes a diversas historias, luego confunde las acciones hasta el punto en que Camacho se comienza a preguntar quién es quién. Especialmente evidente es esta situación en el cap. XVI ${ }^{39}$. Esta confusión es percibida por los locutores y auditores del programa (y por el lector), los cuales comienzan a preocuparse por la salud mental de Camacho, mas luego se interpreta la confusión como "un elemento de tensión" premeditado de Camacho y como una muestra más de su inconmensurable talento artístico.

La novela se caracteriza por su carácter fragmentario, por su heterogeneidad y diversidad. Esta introduce como referente, a través de un juego deconstruccionista, intertextual, como así también a través de la ironía y parodia, el género de la radio-novela y de las mencionadas novelas episódicas, pero los temas de Camacho se diferencian por completo de los de este género, es decir, no tienen ni la cursilería ni el clisé de la novela rosa de radio (a lo Corín Tellado). Los episodios presentan una vasta gama de destinos de personajes de diversísima proveniencia, que representan el paisaje completo de la sociedad peruana (y latinoamericana): tematiza a la oligarquía, a los intelectuales, a la gente de negocios, a la iglesia, a la pobreza, a la policía, a la gente media, a los futbolistas, a las familias venidas a menos, etc.

La crítica no es aquí tan evidente como en las novelas anteriores de Vargas Llosa, sino que ésta se deja sutilmente en manos del lector implícito: solamente de la historia narrada, sin comentario alguno, y sin el recurso a oposiciones binarias, se desprende una crítica social agudísima, sea a través de la descripción descarnada de concepciones morales rígidas hasta lo patológico, sea a través de la descripción de un autoritarismo enfermizo o de la pobreza más cruel y su adjunto la violencia. Ejemplos serían el incesto entre Richard y su hermana Elianita (cap. II), la violación de una menor de edad y la negación del hecho por el violador que para probar su inocencia se corta el penis (cap. VI), o aquel episodio donde la hermana de Federico Tellez es devorada por ratas gigantescas y la transformación de Tellez, como consecuencia de esta experiencia, en un déspota enfermizo que al final es asesinado por su propia familia (cap. VIII).

Los episodios de Camacho van teniendo crecientemente algo de horroroso y mórbido, la violencia y la eliminación de los personajes va siendo cada vez más monstruosa. De esta forma se "deconstruye" el modelo tradicional de la radio novela y se reemplaza por otro.

Este cambio se manifiesta claramente, p.e. en el mencionado episodio del incesto, donde se emplea un discurso típico de la radio-novela: Richard es la

${ }^{30}$ Usamos la edición de Seix Barral/Biblioteca de Bolsillo, Barcelona, 1984. 
esencia misma de la perfección, proviene de la oligarquía, es por esto rico, un Adonis, un estudiante extraordinario, estupendo deportista y danzarín, un hijo mimado y admirado por toda la familia, un hijo ejemplar, es admirado y amado por todos su amigos; en una palabra, tiene todas aquellas características que se le dan en este tipo de literatura o de radio-novela a chicos de la clase alta que salen algo de la mediocridad intelectual, que allí por lo general reina, y se les transforman en mito. A su hermana se le adjudican los mismos adjetivos. Mas luego caen en la infelicidad, en un tipo de desgracia que es sancionada por la sociedad.

Otra base de esta novela está constituida por una reunión de citas, tanto de contenido como formales, de los sistemas novelísticos de los siglos XVIII, XIX y XX, de Laclos, Balzac, Flaubert, Zola y Borges ${ }^{40}$, donde los personajes siempre retornan, donde hay personajes que están afectados por "herencias genéticas". La diferencia con los sistemas decimonónicos radica en que Vargas Llosa no analiza la psique de los personajes, sus vitae y pasados como así tampoco sus problemas genéticos.

El modelo de Balzac se encuentra solamente como cita, no como sistema de base, en el cap. $X$, donde un suave joven, que tiene todas las características del héroe romántico se radica en una pensión de baja categoría (como la Pensión Vauquer en Le père Goriot) y desata su pasión hasta entonces oculta. En forma esquizofrénica, con una carga criminal tal que se transforma en un demonio, acuchilla al dueño de la pensión, (que le tiene gran simpatía), mientras duerme, y luego viola o trata de violar a su mujer (esto no queda claro). Finalmente se le encierra en un manicomio. También Camacho, el escritor radial, concebido según parámetros del genio romántico, termina parando en el manicomio.

La Education sentimentale de Flaubert se encuentra inscrita en la relación entre Mario y Javier (como en la novela de Flaubert entre Frédéricy Deslauriers). Los amigos constatan, después de algún tiempo, que "han madurado psicológicamente ${ }^{\text {"41 }}$, lo cual es una reminiscencia de esta novela, como también de las observaciones que hace el narrador omnisciente en Père Goriot con respecto Rastignac después de la muerte de Goriot.

La historia de amor entre Mario y su tía Julia es una ironización y casi parodia de Liaisons dangereuses (aquí también denominada “juegos peligrosos"42), en la cual las cartas se reemplazan por el teléfono, y los encuentros siempre acarrean peligro.

El juego metatextual se encuentra en todos aquellos momentos donde el narrador reflexiona sobre los procedimientos narrativos, 0 allí donde la ficcionalidad es descubierta como tal, y conocidos datos autobiográficos del autor son empleados como juego referencial.

${ }^{40}$ A Balzac se le cita en cap. III, p. 65 y cap. XV, p. 329; a Zola en cap. II, p. 37; a Borges en cap. III, 59 .

${ }^{41}$ Cap. XI, 249.

${ }^{42}$ Cap. IX, 196. 
En el cap. II, pág. 64-65 se citan los procedimientos realistas de la organización de los personajes y de la acción, los cuales son descubiertos como una alta mitización de la realidad y por esto como absolutamente carentes de legitimación histórica y mucho menos científica. Camacho se basa para la creación de sus episodios radiales en un mapa de la ciudad de Lima, con la finalidad "de describir la vida real". Este objetivo resulta ser una ilusión y sus radio-novelas, el producto de una imaginación desaforada. Camacho describe en forma arbritaria y sin conocimiento de Lima ni de sus habitantes (de hecho jamás abandona el estudio de la radio y su cuarto privado), a los cuales les atribuye características tanto sociológicas como morales falsas, como constata $\mathrm{Mario}^{43}$, atraído por casos extremos, algo típico del romanticismo, del realismo de Balzac y el naturalismo de Zola. Con esto no solamente se descubre la ficción como ficción en el juego narrativo, sino que a la vez se tematizan los criterios de selección y de tipización de los personajes en la literatura decimonónica declarándola como un producto de la fantasía, a pesar de su ideología empirista.

Otros procedimientos citados se encuentran en aquellos episodios donde se pasa a lo fantástico, donde las acciones son absolutamente a-causales, fragmentarias y sin explicación ninguna. En estos episodios se cita a Borges reflexionando sobre el 'salto cualitativo', y citando así algunos postulados poetológicos de Vargas Llosa sobre la "nueva novela"4.

Esta novela es finalmente una descripción de cómo nace una ficción, del proceso creador, mas por un camino opuesto al del nouveau roman $n^{45}$.

\subsubsection{La novela de la 'intrahistoria': $1975 \ldots$}

Bajo esta rúbrica contamos con novelas tales como las de Alejo Carpentier El recurso del método (1974), García Márquez Elotoño del patriarca (1975), Carlos

${ }^{43}$ Cuando Mario protesta contra las clasificaciones contesta Camacho: "-No se trata de una clasificación cientifica sino artística-me informo [...]. No me interesa toda la gente que compone cada barrio, sino la más llamativa, la que da a cada sitio su perfume y su color. Si un personaje es ginecólogo debe vivir donde le corresponde y lo mismo si es sargento de la policía.

Me sometió a un interrogatorio prolijo y divertido (para mi, pues él mantenía su seriedad funeral) sobre la topografía humana de la ciudad y advertí que las cosas que le interesaban más se referían a los extremos: millonarios y mendigos, blancos y negros, santos y criminales"; ibid.: III, pág 65.

44 Ibid. cap III, 58-59.

${ }^{45}$ Lo dicho se manifiesta p.e. cuando se describen las preferencias o los odios que tiene Camacho frente a temas y procedimientos que son una especie de hilo de Ariadna en la novela: los argentinos, tan odiados por Camacho, son siempre presentados como criminales, sucios, ladrones y perversos (esto es producto de su experiencia profesional con argentinos), sus héroes son de una edad ideal de cincuenta años (que es su propia edad) y se parecen físicamente al radio novelista. 
Fuentes, Terra Nostra (1976), Roa Bastos, Yo el Supremo (1977), Vargas Llosa, La guerra del fin del mundo (1983) y García Márquez, El general en su laberinto (1989).

Como ejemplo queremos solamente comentar la novela de Roa Bastos, Yo el Supremo (1977).

La novela se concentra - como sabemos-en el período del dictador Dr. José Gaspar Rodríguez de Francia (1814-1840), como así también en el carácter de este personaje, mezcla bizarra proveniente, por una parte, de la tradición del enciclopedismo francés del dieciocho (Rousseau, Montesquieu), de la época napoleónica, y del romanticismo. Por otra parte, encontramos la mentalidad del autoritarismo patriarcal-feudal de la tradición de los terratenientes latinoamericanos. Esta novela de Roa Bastos no toma partido en pro o en contra de la muy discutida y ambigua personalidad del dictador, sino que trata de aclarar la dimensión histórica de este personaje y de este período, que es representativo para la historia general de Latinoamérica hasta nuestros días, a través de una complejísimay diferenciadísima estructura siempre en evolución y cuestionando su propio discurso ${ }^{46}$.

El marco general de la comunicación se caracteriza por la relación entre el Supremoy su secretario Policarpo Patiño, que a su vez es su escribano, como así también por la división del Yo del Supremo que se concreta en una estructura Yo-El, y finalmente por dos editores, un corrector y un compilador.

La novela se puede estructurar partiendo de sus diversos temas en la forma siguiente: 1. El Pasquín; 2. los apuntes, un texto que contiene los diálogos entre el Supremo y Patiño; 3. el cuaderno privado, en el cual el dictador lleva cuenta del comienzo de su gobierno por propio puño y letra los gastos públicos, luego agrega -como indica el editor-diversos pensamientos, sucesos y reflexiones, tanto importantes como banales sobre una gran gama de temas y campos sin un orden determinado. Este escrito es una especie de diario, un lugar de refugio, donde el dictador describe su política y su vida; 4. La circular perpetua que son decretos y dictámenes para los funcionarios estatales que se los dicta a Patiño; 5. las notas, que se encuentran en forma de notas a pie de página, por lo general se encuentran impresas con una letra más pequeña, separadas del texto principal, o se encuentran entrelazadas en el texto en forma de observaciones y breves digresiones (en total son 73 ); 6. cuaderno de bitácora, en el cual se

\footnotetext{
46 El punto inmediato de partida de la novela es una pasquín anónimo, en el cual se encuentra escrito un texto con la misma caligrafía y estilo del dictador. En éste se ordena que el cadáver del dictador sea ultrajado públicamente y luego quemado, y que sus aliados politicos sean ejecutados. Con respecto a la au toría del pasquín existen varias posibilidades: una es que el autor sea el mismo dictador que emplea el pasquín como pretexto para aniquilar a sus enemigos; la segunda consiste en que el dictador mismo haya escrito el pasquín, pero que, debido a la división de su Yo, no lo sepa; y tercero, el pasquín puede haber sido escrito por sus enemigos, como advertencia al dictador.
} 
describe en forma fragmentaria el pasado del dictador, y finalmente 7. otros textos no clasificables que aparecen esporádicamente, muchas veces al borde del texto.

Yo el Supremo se puede considerar, partiendo de su renovación lingüística y de la forma intertextual del trato ficcional de la historia, como una obra magistral y decisiva de la post-nueva novela, respectivamente de la postmodernidad literaria y de aquéllas escritas en lengua española. El empleo de la intrahistoria, es decir, de la interacción de diversas series codificadas del conocimiento, aquí precisamente de la historia y la ficción, del empleo funcional de estos discursos con la finalidad de aclarar fenómenos radicados en la profundidad del sistema de la cultura que en su superficie aparecen al nivel del conocimiento como hechos irrefutables y en muchos casos contradictorios e inexplicables, el trato de la historia como un todo cultural, como un fenómeno semiótico, la intrahistoria como nueva forma de ver, es un objeto dominante en esta novela. A través de este procedimiento se interpretan, por una parte, las contradicciones, la pluralidad, las rupturas y la discontinuidad de la historia y de la cultura latinoamericana, en este caso concretada en la personalidad del dictador y unida al empleo de diversos tipos de discursos y mediadores. Por otra parte se hace accesible la cultura de este continente a un lector ajeno a él. 
